\section{A SOCIEDADE EM REDE}

Manuel Castells

São Paulo: Paz e Terra, 1999.

\section{Rainer Randolph}

A literatura sobre globalização e mundialização, sobre reestruturação econômica e mudança de regime de acumulação e regulação, sobre surgimento de novas formas de organização e integração econômica e social por intermédio de redes de computadores, sobre enfraquecimento dos Estados nacionais e o possível advento de uma assim chamada condição pós-nacional (Habermas, J. Die postnationale Konstellation. Frankfurt/M.: Suhrkamp, 1998) e outros temas ligados a esses assuntos, está crescendo como uma bola de neve desde o início da década de 1990. Observa-se, particularmente no ano de 1996, a nosso ver, um excepcional avanço do debate a partir da publicação de contribuições importantes de autores como David Harvey (Justice, nature \& the geography of difference. Malden, Mass. Oxford: Blackwell, 1996), Edward Soja (Thirdspace. Cambridge, Mass. Oxford: Blackwell, 1996), Stephen Graham e Simon Marvin (Telecommunications and the city. London, New York: Routledge, 1996) e, last but not least, Manuel Castells (The rise of the network society. Malden, Mass. Oxford: Blackwell, 1996).

O sociólogo espanhol Castells, atualmente radicado nos EUA, abre com seu livro, cuja tradução para o português sob o título $A$ sociedade em rede (São Paulo: Paz e Terra, 1999, já na segunda edição) é objeto da nossa resenha, a trilogia Era da Informação: economia, sociedade e cultura, que vai se completando nos anos subseqüentes com os livros The power of identity (1997), já disponível em português na mesma editora, e End of millenium (1998).

Entre os autores mencionados, Manuel Castells parece o único que, desde o princípio do primeiro volume da trilogia, anuncia que não pretende discutir as teorias existentes sobre o pós-industrialismo ou a sociedade da informação, uma vez que já existem "várias apresentaçôes abrangentes e equilibradas dessas teorias, bem como várias críticas, inclusive as minhas" (p.41). Dedica-se, no seu livro, a "construir o discurso mais autônomo e não redundante possível, integrando materiais e observações de várias fontes" (p.45) que possam, então, fornecer um abrangente pa- norama daquelas transformações que, talvez, estejam anunciando o fim de uma era, a do capitalismo e da cidade industrial.

Já os outros autores acima mencionados dedicam grande parte de seus esforços exatamente àquilo que Graham e Marvin chamam de desafio paradigmático, que precisa ser enfrentado para elaborar novas orientações de compreensão e interpretação, "desafio" que leva Harvey e Soja - cada um à sua maneira - a buscar um sustento "paradigmático" na dialética.

Abdicando explicitamente de uma reflexão crítica, o livro de Castells traz, nos seus sete capítulos, uma riqueza enorme de fatos e acontecimentos a respeito das mudanças que ocorreram e estão ocorrendo ao redor do globo, responsáveis pela formação de uma verdadeira economia global (distinta da forma mundial que a antecede).

Abre para o leitor o universo extraordinário da revolução tecnológica atual (primeiro capítulo); da constituição de uma economia informacional no nível global (segundo capítulo); de seus protagonistas principais, isto é, dominantes em forma de empresa em rede (terceiro capítulo); da transformação do trabalho e do mercado de trabalho (quarto capítulo); e da sua face "cotidiana" nas redes interativas, mediante a integração à comunicação (quinto capítulo).

Nos dois últimos capítulos, discute a formação e a consolidação de um novo espaço industrial, que vai evoluindo para uma oposição entre um "espaço dos fluxos" (capital) e um "espaço dos lugares" (trabalho), gerando, enfim, no limiar do eterno, um "tempo intemporal".

Na parte final do livro, Castells conclui que a exploração das estruturas sociais emergentes, realizada no decorrer dos capítulos anteriores, que se referem a diferentes domínios de atividades e experiências humanas, leva-o a uma inquestionável afirmação: "como tendência histórica, funçôes e processos dominantes na era da informação estão organizados, cada vez mais, em torno de redes" (p.497). Destaca que as "redes constituem a nova morfologia social das atuais sociedades, e a difusão da lógica de rede modifica substantivamente a operação e o resultado dos processos produtivos, experiência, poder e cultura”.

Em princípio, tal forma de organização social em rede - já existia em outros tempos e espaços (períodos e territórios). Mas o novo paradigma da tecnologia de informação fornece a base material para uma 
expansão que permeia a estrutura social inteira. Castells argumenta que essa lógica de produzir redes (networking) induz a uma determinada lógica social que se localiza num patamar superior, em que os interesses sociais específicos se expressam por meio das tradicionais redes (de influência). De uma maneira sintética, aponta que, hoje, o poder de fluxos assume uma precedência em relação aos fluxos do poder.

É essa hipótese - anunciada antes quando retoma com o "espaço de fluxos" uma idéia já do livro Informational city - que ele vai explicitar mais detidamente nesse capítulo conclusivo. Argumenta que, sob as condiçôes da sociedade-rede, "o capital é coordenado globalmente, o trabalho é individualizado. A luta entre os diversos capitalistas e as classes de trabalhadores miscelâneos está subsumida à oposição mais fundamental entre a lógica nua de fluxos de capital e os valores culturais da experiência humana" (grifos nossos).

Para chegar a essa conclusão, realiza uma ampla reflexão acerca das novas relações entre capital e trabalho, que se instalam na sociedade-rede organizada "em torno de redes globais de capital, administração de empresas e informação, cujo acesso ao saber tecnológico (know-how) está nas raízes da produtividade e competitividade".

A propagação e ampliação das redes (networking) no interior e entre empresas, corporaçóes e mesmo organizaçôes que não visam ao lucro não podem ser interpretadas como morte do capitalismo. Ao contrário, representa uma jamais vista expansão do modo de produção capitalista que molda relacionamentos sociais ao redor do planeta inteiro: "A sociedade-rede, nas suas várias expressões institucionais, é e continuará por algum tempo uma sociedade capitalista". Porém é também profundamente diferente das suas formas históricas anteriores, uma vez que é (a) global e (b) estruturada em larga medida em torno de uma rede de fluxos financeiros.

Conseqüentemente, não há uma "classe capitalista” em nível mundial, mas existe, segundo Castells, uma integrada rede capitalista global, cujos movimentos e lógica variável determinam economias e influenciam sociedades. Portanto, para além de uma diversidade de capitalistas de carne humana e grupos capitalistas, existe um capitalista coletivo sem rosto, gerado por fluxos financeiros em redes eletrônicas. Após essa "dissolução ou fluidificação" do capital (sob domi- nação do financeiro) nas redes globais dos fluxos de informações, o que, pergunta-se o autor, aconteceu com o trabalho, os trabalhadores e as relaçóes sociais de produçãao? Os trabalhadores não desapareceram (no "espaço dos fluxos") e, apesar de todos os problemas, basicamente na Europa, afirma que o trabalho é farto.

Entretanto, mesmo existindo trabalho, trabalhadores e classes de trabalhadores, o relacionamento social entre capital e trabalho transformou-se profundamente:

"Na sua essência, o capital é global. Como regra, o trabalho é local."

Em outras palavras: "Assim, enquanto o relacionamento capitalista persiste ainda (ora, em muitas economias a lógica dominante é mais estreito capitalista que nunca antes), capital e trabalho tendem a existir, cada vez mais, em espaços e tempos diferentes: o espaço dos fluxos e o espaço dos lugares; tempo instantâneo de redes computadorizadas versus tempo de relógio da vida diária (cotidiana). Portanto, eles vivem um ao lado do outro, mas eles não se relacionam um com o outro, como a vida do capital global depende cada vez menos de trabalho específico, e mais e mais de trabalho genérico acumulado, operado por uma pequena elite intelectual (brain trust), morando nos lugares virtuais de redes globais."

$\mathrm{Na}$ sociedade-rede, as redes - e, em particular, a meta-rede (dos fluxos financeiros) — não resultam em uma "universalização" de conexões que pudessem superar (aniquilar) velhas separaçôes, segregações ou até exclusões, mas apenas na mundialização do fluxo financeiro. Paradoxalmente, a sociedade-rede caracteriza-se por um grau de conexóes mais baixo do que as formas anteriores. A "distância" entre capital e a expressão coletiva das pessoas é infinita, como Castells afirma em outro momento. A sociedade-rede é aquela em que uma rede (a citada meta-rede) se torna dominante (entre os pares) e excludente (em relação aos trabalhadores e suas manifestações culturais e vitais), como expressão de uma pureza da lógica capitalista nunca vista na História.

Certa radicalidade da posição de Castells não deixa de ter seu fascínio e razão, especialmente quando observávamos à nossa volta um sistema financeiro mundial que parecia enlouquecer sob o ataque de "capitais especulativos" e que, mesmo após os primeiros sustos maiores, não deixa de inquietar bolsas e governos no mundo inteiro. Porém, mesmo assim, sua abor- 
dagem fica limitada — não avança para um questionamento de paradigmas conceituais vigentes - , porque continua presa a uma compreensão restrita das redes como conjuntos de "nós interconectados. Um nó é um ponto no qual uma curva apresenta uma interseção com ela mesma (intersects itself). O que um nó é, falando concretamente, depende da espécie da rede concreta da qual estamos falando".

Para Castells, as redes permanecem como estruturas (abertas, aptas a se expandirem, comunicativas, altamente dinâmicas) e instrumentos econômicos, sociais e culturais. Cada rede tem sua topologia, determina distâncias, velocidades (até mesmo simultaneidades) e precisa, naturalmente, de certos suportes materiais, energéticos e informacionais para poder desempenhar suas funçóes.

Não consegue superar (no sentido hegeliano) vieses instrumentalistas, estruturalistas e funcionalistas. Para isso, a rede precisaria ser conceituada, a nosso ver (vide também em particular Ilse SchererWarren), como uma nova forma ("dialética"?) de "integração da diversidade", como a busca de formas de "articulação entre o local e o global, entre o particular (específico) e o universal, entre o uno e o diverso, nas interconexões das identidades dos atores com o pluralismo" (Ilse Scherer-Warren, Redes de movimentos sociais. São Paulo: Loyola, 1989). Ou seja, articulaçôes que transcendem as formas tradicionais de "sistemas" (e igualmente não-sistemas como o mundo da vida, o cotidiano, as determinações de um quadro institucional de uma sociedade), "estruturas" e mesmo morfologias aparentemente homogêneas. Em síntese, as redes encontram-se num "ponto de intersecção" entre uma heterogeneidade de conteúdos (econômicos, sociais, políticos e culturais) e uma heterogeneidade de formas (locais, regionais, nacionais e mundiais). Uma "sistematização" da concepção das redes poderia usar ambas as dimensóes como maneira de identificar suas características (sua "novidade" em relação a abordagens concorrentes).

Em síntese, à primeira vista e um tanto surpreendente e paradoxal, a análise de Castells parece resultar numa perspectiva "conservadora" da nova sociedade: ao focalizar a convergência de tecnologia e evolução social, as mutações provocadas pela geração de uma nova base material instalam "apenas" uma nova unidade de condução da diversidade do mesmo tipo: uma meta- rede torna-se dominante mundialmente, conduz os processos e molda toda a estrutura social.

Essa meta-rede financeira pode parecer, por um lado, uma última e derradeira manifestação das redes tradicionais que procuram impor-se pela sua lógica unívoca e dominar outras formas de dinâmicas econômicas, sociais, políticas e culturais. Mais um sinal do fim de um ciclo do que marca de um novo tempo, seja em forma de uma sociedade-rede ou de outra opinião defendida também por certos autores, como Arrighi, por exemplo.

Por outro lado, e parece esta a interpretação sugerida pela análise de Castells, mas não defendida por ele, a meta-rede deve ser compreendida como expressão máxima dos novos tempos que provoca uma total desterritorialização e des-historicização. Significa, portanto, mais que um simples fim do território e da história, na medida em que reverte permanentemente início e fim, próximo e distante, sob uma lógica em que o futuro já esteve presente no passado, e o presente nada mais será que o passado tornado promessa do futuro. Em síntese, a expressão de uma dinâmica incontrolável, cuja própria lógica sem espaço e tempo apenas pode cumprir-se num caos, em que a única "razão" (como domínio de outras expressóes) consiste na sua própria reprodução como caos.

Será a instalação da entropia como princípio "social" máximo de uma rede das redes, cuja única "finalidade" será a de destruir outras finalidades, isto é, voltar-se-á contra todas as tentativas de reduzir a entropia do "sistema" (mediante a geração de ordenamentos, articulações e organizações, regulações e instituições etc.). Significará a reversão de todos os processos, o abandono de uma dinâmica com lógica - e, portanto, de todas as lógicas; sem espaço - portanto, em todos os espaços; sem tempo - portanto, em todos os tempos; sem protagonista - e, portanto, de todos os sujeitos. Será a manifestação da antítese de todas as teses, de uma força onipresente e onipotente imprevisível e incontrolável que não está em lugar nenhum, mas em todos ao mesmo tempo e nunca.

Portanto, nem eternidade, nem fim da História: mas, provavelmente, fim da humanidade.

Rainer Randolph, economista, é professor do Institututo de Pesquisa e Planejamento Urbano e Regional da Universidade Federal do Rio de Janeiro. 